\title{
Role of Condylar Plate for the Treatment of Intercondylar Fracture of Femur
}

\author{
Dr. Mohammad Ali Hossain ${ }^{1 *}$, Dr. S. K. Kamal Uddin ${ }^{2}$, A. S. M. Iqbal Hossain Chowdhury ${ }^{3}$
}

${ }^{1}$ Senior Consultant, Department of Orthopedic, 250 Bedded District Sadar Hospital, Cox's Bazar, Bangladesh

${ }^{2} \mathrm{MO}$, Department of Orthopedic, 250 Bedded District Sadar Hospital, Cox's Bazar, Bangladesh

${ }^{3}$ Associate Professor (cc) OSD. DGHS. Attached, Department of Orthopedic Surgery, Sheikh Hasina Medical College, Jamalpur, Bangladesh

DOI: $10.36347 /$ sjams.2020.v08i05.008

| Received: 07.04.2020 | Accepted: 14.04.2020 | Published: 06.05.2020

*Corresponding author: Dr. Mohammad Ali Hossain

Objective: In this study our main goal is to evaluate the outcome of the efficiency of the Condylar plate for the treatment of intercondylar fracture of femur. Method: This clinical trial was carried out at tertiary medical college and hospital between June 2014 to June 2015. A total of 40 patients of intercondylar fractures of femur meeting the selection criteria were consecutively included in the sample. Results: During the study, over half (53.3\%) of the patients were operated after $1-2$ weeks of receiving the injury, 26.7\% before 1 week and $20 \%$ after $2-3$ weeks of injury. Two-thirds $(66.7 \%)$ of the patients stayed in the hospital for 2-3 weeks and the rest > 3-4 weeks. After intervention where $40 \%$ of the patients had excellent outcome (Insal score > 85), 46.5\% good outcome (Insal score between 70-84), and 13.5\% fair outcome (Insal score 60 - 69). Conclusion: The outcome of intercondylar fractures of the femur treated by condylar plate demonstrated excellent to good result in majority of the cases. Sixty percent of the cases returned to routine preinjury activities without limitations and one-quarter with mild limitations, in terms of subjective evaluation as well most of the patients had good to excellent outcome.

Keywords: Condylar plate, intercondylar fracture.

Copyright @ 2020: This is an open-access article distributed under the terms of the Creative Commons Attribution license which permits unrestricted use, distribution, and reproduction in any medium for non-commercial use (NonCommercial, or CC-BY-NC) provided the original author and source are credited.

\section{INTRODUCTION}

Supracondylar and intercondylar fractures of the distal femur historically have been difficult to treat. Numerous devices have been proposed and supported and practiced by various authors and centre. Regardless of the implant that has been used for the treatment of distal femoral fracture the principle of internal fixation has to be met. These include proper anatomic reduction of the distal femoral joint surface, stable fixation of the fracture providing proper correction of shortening, angulations and rotational deformities yet permit some stress to allow for rapid and complete healing of fracture, minimal soft tissue stripping and early active mobilization [1-3].

Now most of the intercondylar fractures are being treated by DCS and condylar plate. For DCS a minimum of $4 \mathrm{~cm}$ of uncomminuted bone in the femoral condyle above the intercondylar notch is necessary for successful fixation. Whereas multiple whole in the distal part of condylar plate allow multiple screws to be directed into comminuted fractures. However, different investigators claimed dubious results of intercondylar fracture of femur fixation by condylar plate $[4,5]$.
In this study our main goal is to evaluate the role of Condylar plate for the treatment of intercondylar fracture of femur.

\section{OBJECTIVE}

\section{General objective}

- To assess the role of Condylar plate for the treatment of intercondylar fracture of femur.

\section{Specific Objectives}

- To detect types of injury.

- To identify operative outcome of the patients

\section{MethodologY \\ Study Type}

- The study was a clinical trial.

\section{Place and period of study}

- The study was carried out at the tertiary medical college and hospital between June 2014 to June 2015. 


\section{Inclusion Criteria}

- Adult patients of $>18$ years irrespective of sex

- Intercondylar femoral fractures of Muller Type $\mathrm{Cl}, \mathrm{C} 2$ and $\mathrm{C} 3$.

- Both closed and open fractures, Gustillo-I, II

\section{Sample Size}

- A total of 40 patients of intercondylar fractures of femur meeting the above selection criteria were consecutively included in the sample.

\section{METHOD}

- Data were collected using a structured questionnaire (research instrument) which contained all the variables of interest. In all cases a detailed history and clinical examination were done. Relevant investigations like complete blood count, random blood sugar and serum creatine were done routinely. Any associated illness such as hypertension, diabetes mellitus, pulmonary problem and concomitant injuries were excluded and if present were treated adequately. X-ray of the affected thigh including hip and knee joints (A/P and lateral view) were performed and selected cases were treated by condylar plate under general/spinal anesthesia.

\section{Data Analysis}

- Collected data were analysed using software SPSS (Statistical Package for Social Sciences) version 24 for windows. Descriptive statistics were used to analyse the data. Analysed data were presented in the form of tables and charts with due interpretation.

\section{RESULTS}

In Table-1 shows age distribution of the patients where out of 40 patients, the mean age of the patients was $42.6 \pm 16.1$ years and the lowest and the highest ages were 20 and 70 years respectively. The following table given below in detail:

Table-1: Age distribution of the participants $(n=40)$

\begin{tabular}{|c|c|}
\hline Age (yrs) & Percentage \\
\hline$<30$ & 20.3 \\
\hline $31-40$ & 26.4 \\
\hline$>40$ & 53.3 \\
\hline
\end{tabular}

Mean age $=(42.6 \pm 16.1)$ years; range $=(20-70)$ years.

In Figure-1 shows gender distribution of the patients where most of the patients were male, $73 \%$. The following figure is given below in detail:

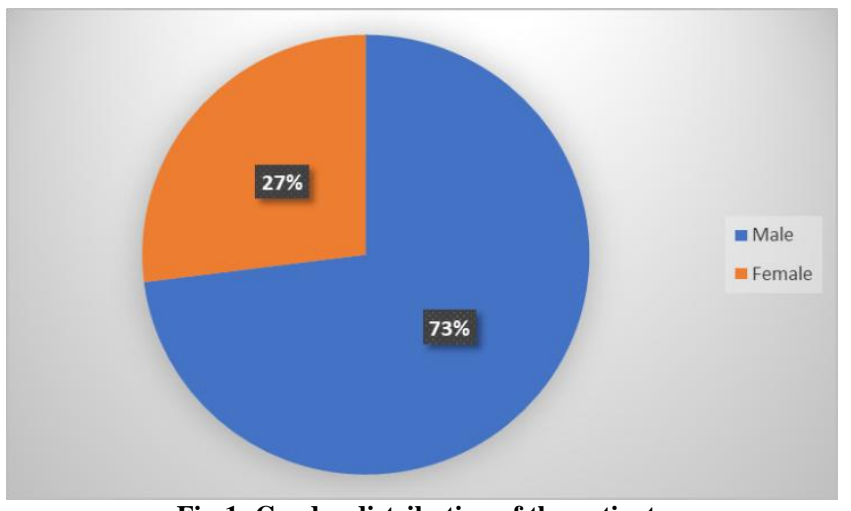

Fig-1: Gender distribution of the patients

In Figure-2 shows distributions of the patients according to types of injury where muller type $C_{2}$ was predominant and muller type $\mathrm{Ci}$ and $\mathrm{C}_{3}$ each was $20 \%$. The following figure is given below in detail:

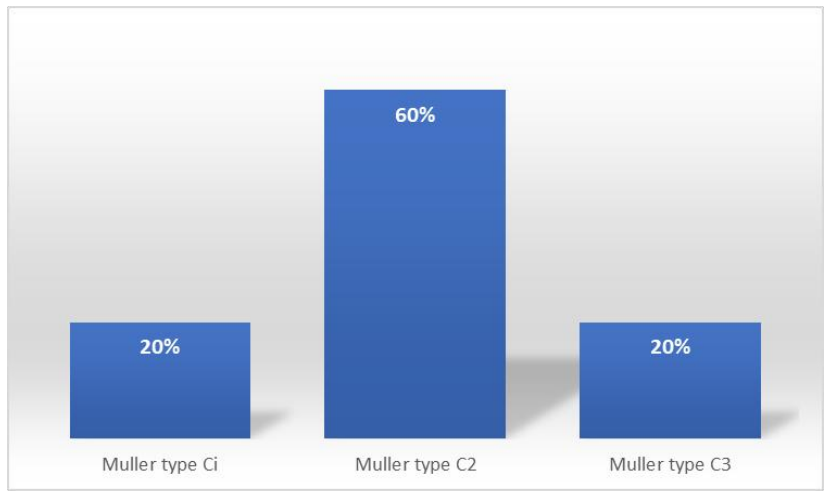

Fig-2: Distributions of the patients according to types of injury 
In Table-2 shows operative outcome of the patients where over half $(53.3 \%)$ of the patients were operated after $1-2$ weeks of receiving the injury, $26.7 \%$ before 1 week and $20 \%$ after 2-3 weeks of injury. Twothirds $(66.7 \%)$ of the patients stayed in the hospital for 2-3 weeks and the rest > 3-4 weeks. The following table is given below in detail:

Table-2: Operative outcome of the patients

\begin{tabular}{|l|l|}
\hline Time interval between & \% \\
\hline injury and operation $<1$ week & 26.7 \\
\hline 1-2 weeks & 53.3 \\
\hline$>2-3$ weeks & 20.0 \\
\hline Duration of hospital stay & \\
\hline 2-3 weeks & 66.7 \\
\hline$>3-4$ weeks & 33.3 \\
\hline
\end{tabular}

In Table-3 shows evaluation of outcome by Insal score 9 months after intervention where $40 \%$ of the patients had excellent outcome (Insal score > 85), $46.5 \%$ good outcome (Insal score between 70-84), and $13.5 \%$ fair outcome (Insal score 60 - 69 ). The following table is given below in detail:
Table-3: Outcome of patients based on Insal score (n = 40)

\begin{tabular}{|c|c|}
\hline Insal score & Percentage \\
\hline$>85$ (Excellent) & 40.0 \\
\hline $70-84$ (Good) & 46.5 \\
\hline $60-69$ (Fair) & 13.5 \\
\hline
\end{tabular}

In Table- 4 shows outcome of patients based on subjective evaluation where $40.1 \%$ of the patients rated the outcome as excellent, $46.6 \%$ good and $13.3 \%$ fair. The following figure is given below in detail:

Table-4: Outcome of patients based on subjective evaluation $(n=40)$

\begin{tabular}{|c|c|}
\hline Subjective evaluation & Percentage \\
\hline Excellent & 40.1 \\
\hline Good & 46.5 \\
\hline Fair & 13.3 \\
\hline
\end{tabular}

In Figure-3 shows outcome of patients based on range of knee motion where $(13.3 \%)$ patients exhibited wide range of knee motion $\left(>130^{\circ}\right),(26.7 \%)$ patients slightly restricted knee motion $\left(130-110^{\circ}\right)$, $(46.7 \%)$ moderately restricted knee motion $\left(110-90^{\circ}\right)$ and $(13.3 \%)$ extremely restricted knee motion $\left(<90^{\circ}\right)$. The following figure is given below in detail:

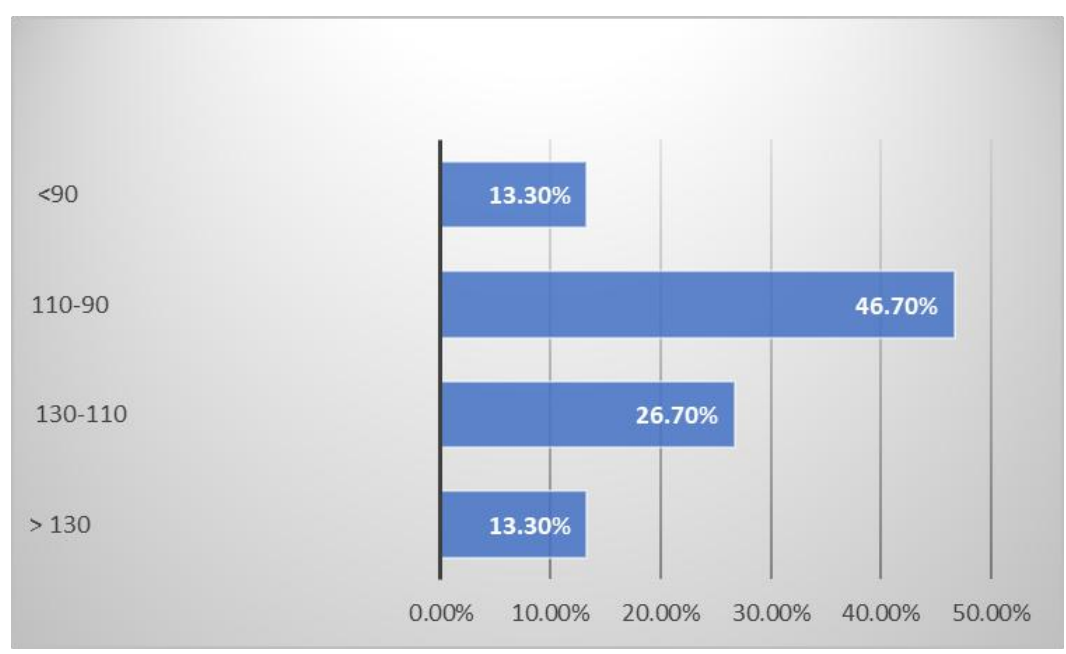

Fig-3: Outcome of patients based on range of knee motion

\section{DISCUSSION}

The treatment of distal femoral fractures may pose difficult problems. Surgery is the preferred treatment in fractures of the distal femur, which accounts for $4 \%$ to $7 \%$ of all femoral fractures. Distal femur fractures occur at approximately one-tenth the rate of proximal femur fractures and make up $6 \%$ of all femur fractures. There is abimodal distribution of fractures based on age and gender. Most high-energy distal femur fractures occur in males between 15 and 50 years, while most low-energy fractures occur hi osteoporotic women $>50$ years. The most common high-energy mechanism of injury is a traffic accident
$(53 \%)$ and the most common low-energy mechanism is a fall at home $(33 \%)$ [6].

One study claimed that "fractures in the distal third of the femur continue to perplex the surgeon, whether they are transverse, oblique, or comminuted, or supracondylar or intercondylar in a $\mathrm{T}, \mathrm{Y}$ or $\mathrm{V}$ fashion their management still evokes much controversy because of the consistently poor results obtained.

Muller type $€ 2$ was predominant and Muller type $\mathrm{Ci}$ and $\mathrm{C}_{3}$ each was $20 \%$. One report demonstrated that $28.6 \%$ intercondylar fractures were Mular type $\mathrm{Cl}$, 46.4\% Mular type C2 and $14.3 \%$ Muller type C3 [7]. 
One study reported that, open methods had good functional results, while only $35.3 \%$ of fractures treated by closed methods had good functional results [8].

In the present study, evaluation of outcome by Insal score 12 months after intervention demonstrated that $40 \%$ of the patients had excellent outcome (Insal score $>85$ ), $46.5 \%$ had good outcome (Insal score between $70-84$ ) and $13.5 \%$ had fair outcome (Insal score $<70)$.

In subjective evaluation as well $40.1 \%$ patients rated theoutcome as excellent, $46.6 \%$ good and $13.3 \%$ fair bearing perfect consistency between subjective and objective evaluations. One report found that, excellent outcome in $25 \%$, good in $39.2 \%$ and fair in $21.4 \%$ which is nearly consistent with our findings [7].

\section{CONCLUSION}

The outcome of intercondylar fractures of the femur treated by condylar plate demonstrated excellent to good result in majority of the cases. Sixty percent of the cases returned to routine preinjury activities without limitations and one-quarter with mild limitations, in terms of subjective evaluation as well most of the patients had good to excellent outcome.

\section{REFERENCE}

1. All F, Saleh M. Treatment of isolated complex distal femoral fractures by external fixation. Injury, 2000;31:139-46.
2. Bolhofner BR, Carmen B, Clifford P. The results of open reduction and Internal fixation of distal femur fractures using a biologic (indirect) reduction technique. Journal Orthop Trauma, 1996;10(6):372-7.

3. Brett DC, Rocca GJD, Murtha YM. Treatment of Acute Distal Femur Fractures. Orthopedics, 2008;43:443-45.

4. Butler MS, Brumback RJ, Ellison TS, Poka A, Bathon GH, Burgess AR. Interlocking intramedullary nailing for ipsilateral fractures of the femoral shaft and distal part of the femur. The Journal of bone and joint surgery. American volume. $1991 \mathrm{Dec} ; 73(10): 1492-502$.

5. Butt MS, Krikler SJ, Ali MS. Displaced fractures of the distal femur in elderly patients. Operative versus non-operative treatment. Journal Bone Joint Surg, 1996;5(78):11O-4

6. Chee SG, Lam KS, Tay BK, Balachandran N. Operative treatment of the intercondylar fracture of the femur, Sing Med Journal, 1988;29:276-80.

7. Cieslik P, Piekarczyk P \& Marczynski W 2007, 'Results of retrograde intramedullary nailing for distal femoral fractures - own experience', Ortop Traumatol

8. Dominguez I, Moro Rodriguez E, De Pedro Moro JA, Cebrian Parra JL, Lopez-Duran Stern L. Antegrade nailing for fractures of the distal femur. Clin Orthop Relat, 1998;350(5):74-90. 